\title{
Determinants of potential drug-drug interaction associated dispensing in community pharmacies in the Netherlands
}

\author{
Matthijs L. Becker · Peter W. J. Caspers · Marjon Kallewaard · Riekert J. Bruinink • \\ Nico B. Kylstra · Siem Heisterkamp • Vincent de Valk • André A. van der Veen · \\ Bruno H. Ch. Stricker
}

Received: 24 May 2006/ Accepted: 13 September 2006/Published online: 23 December 2006

(C) Springer Science+Business Media B.V. 2006

\begin{abstract}
Objective: There are many drug-drug interactions (D-DI) of which some may cause severe adverse patient outcomes. Dispensing interacting drug combinations should be avoided when the risks are higher than the benefits. The objective of this study was to identify determinants of dispensing undesirable interacting drug combinations by community pharmacies in the Netherlands.

Methods: A total of 256 Dutch community pharmacies were selected, based on the dispensing of 11 undesirable interacting drug combinations between January 1st, 2001 and October 31st, 2002. These pharmacies were sent a questionnaire by the Inspectorate for Health Care (IHC) concerning their process and structure characteristics.

Main outcome measure: The number of times the 11 undesirable interacting drug combinations were dispensed.
\end{abstract}

M. L. Becker · P. W. J. Caspers · M. Kallewaard .

S. Heisterkamp · A. A. van der Veen

National Institute of Public Health and the Environment,

Bilthoven, The Netherlands

M. L. Becker · B. H. Ch. Stricker ( $₫)$

Pharmaco-epidemiology Unit, Department of Epidemiology

\& Biostatistics, Erasmus Medical Center, PO Box 1738,

3000 DR Rotterdam, The Netherlands

e-mail: bh.stricker@igz.nl

R. J. Bruinink · N. B. Kylstra · B. H. Ch. Stricker

Inspectorate for Health Care, The Hague, The Netherlands

V. de Valk

Drug Information Project, Health Care Insurance Board,

Diemen, The Netherlands
Results: Two hundred and forty-six questionnaires (response rate $96.1 \%$ ) were completed. Dispensing determinants were only found for the D-DI between macrolide antibiotics and digoxin but not for the other 10 D-DIs. Pharmacies using different medication surveillance systems differed in the dispensing of this interacting drug combination, and pharmacies, which were part of a health care centre dispensed this interacting drug combination more often.

Conclusion: Medication surveillance in Dutch community pharmacies seems to be effective. Although for most D-DIs no determinants were found, process and structure characteristics may have consequences for the dispensing of undesirable interacting drug combinations.

Keywords Drug interaction - Drug-drug interaction . Netherlands · Pharmacy · Practice management

\section{Statements on the impact of the article on practice}

- Process and structure characteristics may influence the dispensing of undesirable interacting drug combinations in community pharmacies but probably to a minor degree.

- Medication surveillance in Dutch pharmacies seems to be effective.

\section{Introduction}

Drug-drug interactions (D-DIs) are responsible for many adverse patient outcomes. Different studies 
suggest that D-DIs may cause up to $3 \%$ of all hospital admissions [1-4]. A D-DI is defined as a pharmacokinetic or pharmacodynamic influence of drugs on each other, which may result in desired effects, in reduced efficacy and effectiveness or in increased toxicity [5]. Although many D-DIs exist, only a small part of these D-DIs is clinically relevant [6-8]. The potential benefits of drug combinations should be weighed against the seriousness of the D-DI, taking into account the availability of alternatives. Only in cases that the risks associated with the D-DI are higher than the benefits or if a better alternative is available, the D-DI should be avoided.

In the Netherlands, one of the tasks of the pharmacist is to intervene in case of D-DIs, which involve a high risk for the patient. Hereto, the pharmacist uses patient characteristics and the medication history. All prescriptions, which are submitted to the pharmacy, are screened on potential interactions with the help of medication surveillance software. These D-DIs are evaluated by the pharmacist who intervenes if necessary. This task is important but cumbersome, and requires great attention from the pharmacist. The organisational aspects, such as the tuning of the medication surveillance software and instructions of technicians, should be managed by the pharmacist in such a way that in case of D-DIs with a high risk the pharmacist intervenes. This is important for the prevention of adverse patient outcomes [9].
The objective of this study was to assess process and structure characteristics associated with the dispensing of interacting drug combinations, which carry a high risk of adverse patient outcomes.

\section{Methods}

\section{Setting}

The data for this study were retrieved from the Drug Information Project, a division of the Health Care Insurance Board. This is a database containing the reimbursement data from eight health care insurance companies in the Netherlands. The reimbursement data from January 1st, 2001 until October 31st, 2002 were analysed. Eleven potential D-DIs, that contained a high risk and could be substituted, because a good alternative was available, were selected and counted for each pharmacy in the database. These undesirable potential D-DIs were mostly interactions between chronically used drugs which cannot be interrupted and short-term use of antibiotics or antimycotics, and were selected from the Dutch guidelines for the management of D-DIs (Table 1) $[10,11]$. A D-DI was counted as such, when the chronically used drug was dispensed both in the period 150 days preceding and in the period 150 days after the dispensing of antibiotics or antimycotics for

Table 1 Number of dispensings in the database of the individual drugs involved, the eleven potential D-DIs and the calculated ratio

\begin{tabular}{|c|c|c|c|c|c|c|c|c|}
\hline \multicolumn{3}{|c|}{ Drug-drug interaction } & \multirow{2}{*}{$\begin{array}{l}\text { Number of } \\
\text { dispensings } \\
\text { drug } A \times 1,000 \\
\text { (range) }\end{array}$} & \multirow{2}{*}{\multicolumn{2}{|c|}{$\begin{array}{l}\text { Number of } \\
\text { dispensings } \\
\text { drug } B \times 1,000 \\
(\text { range })\end{array}$}} & \multirow{2}{*}{\multicolumn{2}{|c|}{$\begin{array}{l}\text { Number of } \\
\text { D-DIs counted } \\
\text { (range) }\end{array}$}} & \multirow{2}{*}{$\begin{array}{l}\text { Average ratio } \\
(\text { range })^{\mathrm{a}}\end{array}$} \\
\hline & Drug A & Drug B & & & & & & \\
\hline 1 & $\begin{array}{l}\text { Erythromycin, clarithromycin, } \\
\text { azithromycin, roxithromycin }\end{array}$ & Digoxin & $440.8(0-2754)$ & 487.0 & $(0-3064)$ & 3,993 & $(0-41)$ & $1.39(0-18.52)$ \\
\hline 2 & Itraconazole & Digoxin & $88.7 \quad(0-349)$ & 487.0 & $(0-3064)$ & 245 & $(0-7)$ & $0.45(0-21.69)$ \\
\hline 3 & Ciprofloxacin & Theophylline & $105.4(0-769)$ & 100.9 & $(0-756)$ & 944 & $(0-14)$ & $6.39 \quad(0-$ \\
\hline 4 & Miconazole oral gel & $\begin{array}{l}\text { Acenocoumarol, } \\
\text { fenprocoumon }\end{array}$ & $(0-233)$ & 608.2 & $(5-3156)$ & 154 & $(0-3)$ & $0.38(0-21.30)$ \\
\hline 5 & Erythromycin & Carbamazepine & $49.7 \quad(0-531)$ & 193.6 & $(0-871)$ & 35 & $(0-4)$ & $0.24(0-40.92)$ \\
\hline 6 & $\begin{array}{l}\text { Erythromycin, clarithromycin, } \\
\text { azithromycin }\end{array}$ & Disopyramide & $426.6(0-2754)$ & 9.4 & $(0-151)$ & 61 & $(0-4)$ & - \\
\hline 7 & Erythromycin, clarithromycin & Pimozide & $274.4(0-2004)$ & 57.4 & $(0-394)$ & 70 & $(0-15)$ & $0.46(0-46.12)$ \\
\hline 8 & Propranolol, oxprenolol, pindolol & $\begin{array}{l}\text { beta2-mimetics, } \\
\text { inhalation } \\
\text { corticosteroids }\end{array}$ & $250.6(1-1075)$ & $2,546.9$ & $\begin{array}{l}(27- \\
10504)\end{array}$ & 5,127 & $(0-94)$ & $0.54(0-12.98)$ \\
\hline 9 & Erythromycin, clarithromycin & Cisapride & $274.4(0-2004)$ & 127.5 & $(0-821)$ & 586 & $(0-11)$ & $1.16(0-40.45)$ \\
\hline 10 & $\begin{array}{l}\text { Itraconazole, fluconazole, } \\
\text { ketoconazole }\end{array}$ & Cisapride & $199.9(0-727)$ & 127.5 & $(0-821)$ & 347 & $(0-12)$ & $0.95(0-57.10)$ \\
\hline 11 & Acenocoumarol, fenprocoumon & Azapropazon & $608.2(5-3156)$ & 8.4 & $(0-164)$ & 32 & $(0-19)$ & - \\
\hline
\end{tabular}

a Calculated with Formula 1 
short-term use in the same pharmacy. Pharmacies with less than 5,000 dispensings in the database were excluded.

\section{Procedure}

For each pharmacy, we calculated the dispensing-ratios for the eleven potential D-DIs with Formula 1. This formula was used because the risk of dispensing a D-DI between drug $A$ and drug $B$ is dependent on the number of times each drug is dispensed. The more drug $A$ or drug $B$ are dispensed, the higher the risk that these drugs are combined on the basis of chance alone. In case the dispensing of drug $\mathrm{A}$ is independent from the dispensing of drug B and the D-DI is never intervened, the ratio will on average be one. The number of times this ratio was above one was calculated, because a ratio above one might indicate that medication surveillance fails. In this calculation, there were 342 D-DIs between norfloxacin and theophylline, which were excluded in the analysis because the guidelines concerning the management of this D-DI were inconsistent. Two groups of pharmacies were selected, and the pharmacists were asked in $\mathrm{Au}$ gust 2003 by the Inspectorate for Health Care (IHC) to fill in a questionnaire. The first group included pharmacies with a high risk of dispensing these D-DIs, while the second group consisted of a random sample from the remaining pharmacies. These groups were equal in size. The selection criteria are described in Fig. 1. The selection criterion for receiving a questionnaire $(\geq 4$ times a ratio $>1$ ) was chosen on pragmatic reasons to have enough power for statistical analysis with manageable numbers. A concept questionnaire was composed on basis of a literature search and interviews with experts [9]. The questions concerned process and structure characteristics of several quality aspects and those questions were selected that could discriminate between high and low quality pharmacies. Mostly questions with objective answers were included, for example about written instructions for technicians, filing of data, tuning of the software (which signals were shown and which not) and personnel. The concept questionnaire was tested in three pharmacies and some questions were amended on the basis of their comments. The final questionnaire contained 183 questions, divided into 12 subjects (Table 2). The questionnaire was accessible via the Internet. Pharmacies who had no access to the Internet received the questionnaire by post. Pharmacies who failed to fill in the questionnaire received reminders at regular intervals. A sample from both groups was visited by the IHC (Fig. 1). Also here, the selection criterion ( $\geq 5$ times a ratio $>1$ ) was chosen to have enough power with manageable numbers. Thirty-seven questions from the questionnaire were selected and during the visits these questions were verified. The pharmacies were informed in advance that a selection of the pharmacies would be visited. The selected pharmacies were acquainted after completing the questionnaire. The visiting inspectors were blinded to the number of interacting drug combinations.

Formula 1:

Ratio $1=\frac{k_{i, a b} / N_{i}}{k_{i, a} / N_{i} \cdot k_{i, b} / N_{i}}$

Formula 2:

Ratio2 $=\frac{\frac{k_{i, a b}}{N_{i} \cdot \sum_{i} k_{i, a b} / N_{\mathrm{tot}}}}{\frac{k_{i, a}}{N_{i} \cdot \sum_{i} k_{i, a} / N_{\mathrm{tot}}} \cdot \frac{k_{i, b}}{N_{i} \cdot \sum k_{i, b} / N_{\mathrm{tot}}}}$

where

- $k_{i, a b}$ : number of dispensings of interacting drug combination $\mathrm{AB}$ in pharmacy $i$

- $k_{i, a}$ : number of dispensings of drug A in pharmacy $i$;

- $k_{i, b}$ : number of dispensings of drug B in pharmacy $i$;

- $N_{i}$ : total number of dispensed drugs known in the database in pharmacy $i$;

- $N_{\text {tot }}$ : total number of dispensed drugs known in the database in all pharmacies
Fig. 1 The selection of the pharmacies receiving a questionnaire and IHC visit

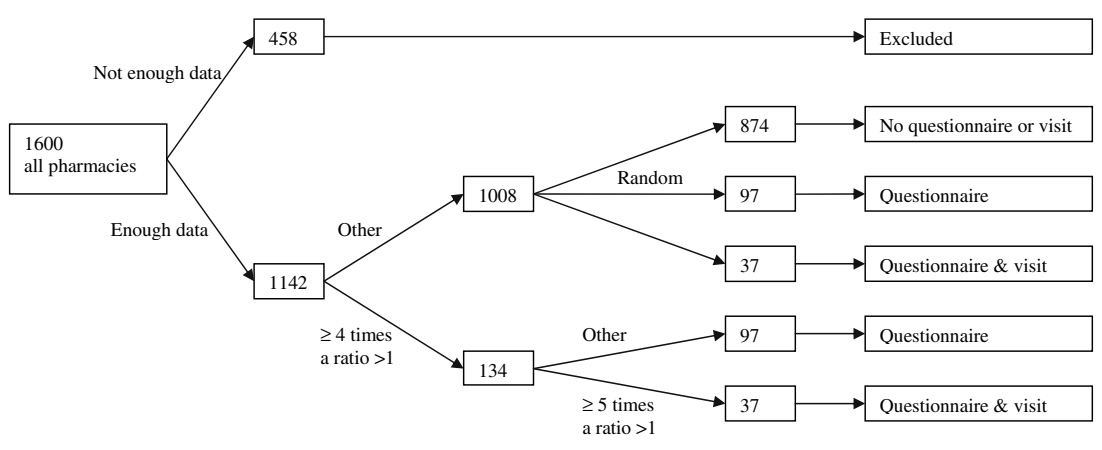


Table 2 The subjects and number of questions in the questionnaire

\begin{tabular}{|c|c|}
\hline Chapter & Subject (number of questions) \\
\hline General pharmacy data & $\begin{array}{l}\text { Ownership of the pharmacy (1), cooperation with other pharmacies (1), cooperation with general } \\
\text { practitioners (1), electronic submission of prescriptions (4) }\end{array}$ \\
\hline Facilities & Alterations (2) \\
\hline Quality policy & $\begin{array}{l}\text { Setting up and implementing a quality system (4), certification (2), attitude towards quality } \\
\text { management (12) }\end{array}$ \\
\hline Quality measurement & $\begin{array}{l}\text { Measurement of errors (2), complaints (1), patient satisfaction (2), interventions (3), and } \\
\text { participation in mystery guest investigations (2) }\end{array}$ \\
\hline Receipt procedure & Number of personnel involved in dispensing a receipt (2), checks in dispensing a receipt (3) \\
\hline $\begin{array}{l}\text { Medication } \\
\text { surveillance-tuning } \\
\text { software }\end{array}$ & $\begin{array}{l}\text { Medication surveillance system used (1), tuning of the system e.g. which signals are showed and which } \\
\text { are regarded as irrelevant }\left(55^{\mathrm{a}}\right) \text {, surveillance of pharmacy preparations }(2)\end{array}$ \\
\hline $\begin{array}{l}\text { Medication } \\
\text { surveillance-organisation }\end{array}$ & $\begin{array}{l}\text { The way technicians are instructed to manage medication surveillance signals (5), the way this is } \\
\text { supervised (2), number of interventions (1), use of resources (2), participation in courses (4), } \\
\text { management of the D-DI between carbamazepine and erythromycin (5) and between } \\
\text { Sulfamethoxazole/trimethoprim and Acenocoumarol (7) }\end{array}$ \\
\hline $\begin{array}{l}\text { Medication surveillance- } \\
\text { recording management }\end{array}$ & The way the management of signals is recorded (4) \\
\hline Pharmacy preparations & $\begin{array}{l}\text { The way instructions for pharmacy preparations are recorded (1), the way pharmacy preparations are } \\
\text { supervised (3), the number of pharmacy preparations (2), the policy regarding analysing pharmacy } \\
\text { preparations (3) }\end{array}$ \\
\hline Personnel and workload & $\begin{array}{l}\text { Subjective workload (3), absence through illness (1), number of receipts dispensed per technician (2), } \\
\text { personnel and experience of personnel (18) }\end{array}$ \\
\hline Patient care & $\begin{array}{l}\text { Information given to patients (6), information exchange with hospitals (4), participation in health } \\
\text { care projects (4) }\end{array}$ \\
\hline $\begin{array}{l}\text { Farmacotherapeutic } \\
\text { consultation groups }\end{array}$ & Participation in farmacotherapeutic consultation groups (3), agreements made (3) \\
\hline
\end{tabular}

${ }^{a}$ As the questions for the four systems (Pharmacom, Aposys, Euroned, others) differed, pharmacists had to fill in only a quarter of these questions

\section{Statistical analysis}

For each pharmacy, dispensing-ratios for the D-DIs, comparable to the standardised mortality ratio, were calculated using Formula 2. With this formula, we standardise for the total number of dispensings per pharmacy in the database. In case all pharmacies dispense the D-DIs in equal numbers, the ratio will be one for all pharmacies, and therefore the ratios have a better comparability. Pharmacies which have only a small number of dispensings in the database, will have extremely high numbers in case they dispense one or a small number of D-DIs. Therefore, the results were equalized with Bayesian statistics to prevent extreme ups and downs due to low numbers of dispensings [12]. The pharmacies were divided into two sets. One set was used for the analyses and contained two-third of the pharmacies, the other set was used for the validation of the results obtained in the analyses. In the univariate analysis, correlations were searched between the answers in the questionnaire and these ratios. Correlations are only given if in both sets a correlation was found $(p<0.01)$. In the multivariate analysis, models were composed using the analysis set, predicting the dispensing of the interacting drug com- binations. The models were validated using the validation set. The number of questions was too large for the multivariate analysis, and only a limited number of questions were selected. From every chapter, those questions were selected that correlated with the other questions and that could discriminate between pharmacies.

\section{Results}

The database contained a total of 100,295,311 dispensings in the selected study period. One thousand one hundred and forty-two pharmacies were recorded in the database with 5,000 or more dispensings. The number of dispensings per pharmacy varied from 5,019 to 264,631 . Because pharmacies receive reimbursements from several health care insurance companies and because not all health care insurance companies were included in the database, these numbers do not correspond with the total number of dispensings per pharmacy. The eleven potential D-DIs were dispensed 11,594 times. In 5\%, more than one pharmacy was involved. As these D-DIs could not be assigned to a single pharmacy, they were excluded from further 
analyses. The number of dispensings and D-DIs are shown in Table 1. Disopyramide (D-DI number 6) and azapropazon (D-DI number 11) were not dispensed by $44 \%$ and $46 \%$ of the pharmacies, respectively. Therefore, a ratio could not be calculated for these pharmacies and these D-DIs were excluded from the analyses.

The number of times a ratio above one was found was calculated (Table 1) and pharmacies were selected as shown in Fig. 1. Two hundred and sixty-eight pharmacies were selected to receive a questionnaire and 74 pharmacies were selected for a visit by the IHC. For several reasons, such as recent visitations and duplications in the database, 12 pharmacies were excluded. Eventually, 256 pharmacies received a questionnaire and 62 pharmacies were selected for a visit. Two hundred and forty-six questionnaires were filled in (response rate $96.1 \%$ ) and $58(93.5 \%$ ) pharmacies were visited after the questionnaire was completed. The judgements during the visits by the IHC were compared with the answers by the pharmacists. In 33 of the 37 verified questions, the IHCs judgement matched in more than $90 \%$ the answer of the pharmacist. Except four questions, the judgement by the IHC was equally more positive and more negative than the answers by the pharmacist.

In the univariate analysis, all combinations between the questions and D-DIs were searched for significant correlations. Two correlations were found with D-DI number 1 between macrolide antibiotics and digoxin (Table 3). Pharmacies, which are part of a health care centre dispensed this interacting drug combination more often than other pharmacies. A correlation with the type of medication surveillance system was also found. Pharmacies using the Euroned system dispensed this interacting drug combination more often, while pharmacies using the Pharmacom system dispensed this interacting drug combination less often.

For the multivariate analysis, 32 variables were selected, representative of the whole range of questions. These variables were used in the analysis-set to com-

Table 3 Significant univariate correlations between the questionnaire and the number of dispensings of the D-DIs between macrolide antibiotics and digoxin (number 1)

\begin{tabular}{lll}
\hline Question & Correlation & Significance \\
\hline Is the pharmacy part of a health care & -0.165 & 0.009 \\
centre? (1 yes, 2 no) (yes $n=18$, no & & \\
$n=228)$ & & \\
Which medication surveillance system & is used in the pharmacy? \\
Pharmacom (1 yes, 0 other $)(n=81)$ & -0.261 & 0.000 \\
Aposys (1 yes, 0 other) $(n=62)$ & 0.088 & 0.170 \\
Euroned (1 yes, 0 other $)(n=89)$ & 0.197 & 0.002 \\
\hline
\end{tabular}

Table 4 Predictability of the models composed in the multivariate analysis

\begin{tabular}{lll}
\hline D-DI & $\begin{array}{l}\text { Adjusted explained } \\
\text { variance }\left(R^{2}\right) \text { (analysis set) }\end{array}$ & $\begin{array}{l}\text { Unexplained variance } \\
\text { (validation set) }\end{array}$ \\
\hline 1 & 28.9 & 0.61 \\
2 & 12.8 & -0.22 \\
3 & 17.3 & 31.5 \\
4 & 7.0 & -0.18 \\
5 & 14.4 & -0.41 \\
7 & 6.5 & 6.4 \\
8 & 16.1 & 0.68 \\
9 & 14.0 & -0.43 \\
10 & 2.6 & 0.90 \\
\hline
\end{tabular}

a An unexplained variance of zero means that the predictability found in the validation set equals the predictability in the analysis-set. The higher the unexplained variance, the worse the predictability in the validation-set compared to the analysis-set

pose models. The adjusted explained variance ranged from $2.6 \%$ to $28.9 \%$ (Table 4 ). The model explaining the D-DI between macrolide antibiotics and digoxin had by far the highest adjusted explained variance. The models were validated in the validation-set, calculating the unexplained variance (Table 4). The six variables in this model explaining the D-DI between macrolide antibiotics and digoxin are shown in Table 5.

\section{Discussion}

In this study, we investigated determinants for the dispensing of 11 undesirable interacting drug combinations. In general, our results are in line with the expectation that the medication surveillance system plays an important role in medication surveillance. Although the 11 potential D-DIs were counted 11,594 times which suggests that a considerable number of patients is exposed to potential and avoidable adverse patient outcomes, these results should be judged against a background of approximately 100 million dispensings. It is possible that in these cases due to particular circumstances any other option, such as substituting or not dispensing one of the drugs, is a less favourable choice than dispensing the D-DI. In $5 \%$ of the total number of D-DIs more than one pharmacy was involved, indicating the importance of communication. For the D-DI between macrolide antibiotics and digoxin, two determinants were found. Although the type of medication surveillance system was a determinant, this does not mean that the differences are determined by the quality of the system itself because they may also correlate with the attitude of the pharmacists using the systems. The three medications surveillance systems differ in the extent to which 
Table 5 The questions in the multivariate model predicting the dispensing of the D-DI between macrolide antibiotics and digoxin (number 1)

\begin{tabular}{|c|c|c|}
\hline Variable: & Answer (coding) & $\begin{array}{l}\text { Direction } \\
\text { coefficient }\end{array}$ \\
\hline Constant & & 3.3679 \\
\hline Is the pharmacy part of a health care centre? (yes $n=18$, no $n=228$ ) & Yes $(0)$ versus no $(1)$ & -2.2749 \\
\hline $\begin{array}{l}\text { Co-trimoxazole-acenocoumarol: no appointments were made with the GPs. } \\
\text { The drug will be dispensed. }\end{array}$ & $\begin{array}{l}\text { Option } 1 \text { 'with all GPs' }(1) \text { versus } \\
\text { other option }(0)(n=11)\end{array}$ & Reference \\
\hline Eight options of choice option 1 'with all GPs' and option & $\begin{array}{l}\text { Option } 2(1) \text { versus other option } \\
\quad(0)(n=10)\end{array}$ & 1.0308 \\
\hline \multirow[t]{6}{*}{ Eight 'with no GPs' } & $\begin{array}{l}\text { Option } 3(1) \text { versus other option } \\
\quad(0)(n=4)\end{array}$ & 0.3788 \\
\hline & $\begin{array}{l}\text { Option } 4(1) \text { versus other option } \\
\quad(0)(n=4)\end{array}$ & -0.4542 \\
\hline & $\begin{array}{l}\text { Option } 5(1) \text { versus other option } \\
\text { (0) }(n=3)\end{array}$ & 0.9026 \\
\hline & $\begin{array}{l}\text { Option } 6(1) \text { versus other option } \\
\quad(0)(n=2)\end{array}$ & -0.5100 \\
\hline & $\begin{array}{l}\text { Option } 7 \text { (1) versus other option } \\
\quad(0)(n=4)\end{array}$ & -0.1912 \\
\hline & $\begin{array}{l}\text { Option } 8 \text { 'with no GPs' (1) versus } \\
\text { other option }(1)(n=202)\end{array}$ & 0.0886 \\
\hline $\begin{array}{l}\text { Are separate signal texts in the medication surveillance program adjusted to the } \\
\text { situation in the pharmacy? (yes } n=72 \text {, no } n=165 \text { ) }\end{array}$ & Yes $(0)$ versus no $(1)$ & 0.1793 \\
\hline $\begin{array}{l}\text { Is the management of signals traceably recorded on the receipt? (yes } n=211 \text {, no } \\
n=35 \text { ) }\end{array}$ & $\begin{array}{l}\text { Yes }(0) \text { on the receipt, no not } \\
\text { on the receipt (1) }\end{array}$ & 0.2691 \\
\hline $\begin{array}{l}\text { The supervision on management of signals takes place on the basis of signal lists } \\
\text { (yes } n=158 \text {, no } n=86 \text { ) }\end{array}$ & $\begin{array}{l}\text { Yes }(0) \text { on the basis of signal lists, } \\
\text { no (1) not on the basis of signal } \\
\text { lists }\end{array}$ & 0.0723 \\
\hline \multicolumn{2}{|c|}{ How many receipts are dispensed per year divided by the number of fte technicians } & $<10^{-4}$ \\
\hline
\end{tabular}

communication with other healthcare providers is possible and developments were made in recent years. The Pharmacom system has the most advanced communication possibilities and compared to the other systems, new developments to the Euroned system were modest. Unexpectedly, pharmacies part of a health care centre dispensed this D-DI more often than other pharmacies. In health care centres, the communication lines between pharmacists and general practitioners are much shorter, suggesting that intervening undesirable D-DIs will be easier. Possibly, pharmacies which are part of a health care centre oppose the opinions from the general practitioners less often, to avoid harming the cooperation within the health care centre but, of course, there may be several other reasons.

For the other eight assessed D-DIs no determinants were found in the univariate analysis, neither did the models in the multivariate analysis have a good predictability. A possible explanation is that the quality of medication surveillance in community pharmacies in the Netherlands is high. Therefore, the number of pharmacies dispensing high-risk D-DIs seems to be small.

Our study has some potential limitations. First, because we used strict inclusion criteria to prevent false-positive results, it is likely that the number of dispensings of undesirable interacting drug combinations in this study is an underestimation and it is possible that important determinants were not recognized or difficult to assess. In the univariate analyses, only those questions are given which had a significant $(p<0.01)$ correlation in two independent sets. Although we included 183 questions and nine D-DIs in the univariate analysis, the possibility of including a significant correlation by chance was small (on average 0.16 question). Second, the reimbursement data from eight health care insurance companies were used. In the Netherlands, these companies work mostly regionally. It is nevertheless not to be expected that the determinants of dispensing interacting drugs differ per region or that pharmacies differ in their management of D-DIs between patients of different health care insurance companies. Third, from all potential D-DIs, only 11 (but highly clinically relevant ones) were selected for this study. According to the Dutch guidelines, for all 11 combinations the dispensing of an alternative was strongly advised as a good alternative was available. Nevertheless, it is possible that these dispensings were not an error because any other option was not possible. For example, when a patient is hypersensitive to the alternative drug recommended in 
the guidelines or when the alternative drug is not effective. In these cases, the benefit of both drug therapies should be weighed against the potential risks of the D-DI. The potential risks can partly be avoided by taking appropriate measures such as monitoring of drug levels. In this study, we could not retrieve why the pharmacist had dispensed the interacting drug combination, and whether the dispensing was erroneous or not.

Fourth, the questionnaire was composed on the basis of a literature search and interviews with experts. It is possible that not all characteristics correlating with the dispensing of undesirable interacting drug combinations were disclosed, such as differences in population characteristics between pharmacies. For example, pharmacies with an elderly population using more drugs simultaneously have a higher risk of dispensing interacting drug combinations than pharmacies with a younger population. Also, it is possible that in areas with many general practitioners who use a medication surveillance system for prescribing, the background chance of a D-DI is much smaller. Fifth, it is possible that the differences between pharmacies were too small compared with the power of this study to distinguish determinants.

All associations found in this study were directly related to the management of signals. In our questionnaire, we also included other topics, such as pharmacy preparations and patient care. Future research should focus on the management of a larger variety of signals than the ones in our study and on how D-DI associated dispensing could be further reduced.

\section{Conclusion}

In conclusion, both medication surveillance systems and being part of a health care centre may play an important role in the management of D-DIs and the avoidance of adverse patient outcomes. Pharmacies in a healthcare centre dispensed D-DIs more often. For most D-DIs, no determinants were found possibly indicating that the quality of medication surveillance in the Netherlands is high.

Acknowledgement This study was funded by the Inspectorate for Health Care.

\section{References}

1. Huic M, Mucolic V, Vrhovac B, Francetic I, Bakran I, Giljanovic S. Adverse drug reactions resulting in hospital admission. Int J Clin Pharmacol Ther 1994;32:675-82.

2. Jankel CA, Fitterman LK. Epidemiology of drug-drug interactions as a cause of hospital admissions. Drug Saf 1993;9:51-9.

3. McDonnell PJ, Jacobs MR. Hospital admissions resulting from preventable adverse drug reactions. Ann Pharmacother 2002;36:1331-6.

4. Peyriere $\mathrm{H}$, et al. Adverse drug events associated with hospital admission. Ann Pharmacother 2003;37:5-11.

5. Schalekamp T. Omgaan met geneesmiddeleninteracties. Geneesmiddelenbulletin 1997;31:87-94.

6. Merlo J, et al. Prescriptions with potential drug interactions dispensed at Swedish pharmacies in January 1999: cross sectional study. BMJ 2001;323:427-8.

7. Bergendal L, Friberg A, Schaffrath A. Potential drug-drug interactions in 5,125 mostly elderly out-patients in Gothenburg, Sweden. Pharm World Sci 1995;17:152-7.

8. Linnarsson R. Drug interactions in primary health care. A retrospective database study and its implications for the design of a computerized decision support system. Scand J Prim Health Care 1993;11:181-6.

9. Becker ML, Kallewaard M, Caspers PW, Schalekamp T, Stricker BH. Potential determinants of drug-drug interaction associated dispensing in community pharmacies. Drug Saf 2005;28:371-8.

10. Stichting Health Base. Commentaren Medicatiebewaking-Pharmacom Medicom. Stichting Health Base, Houten; 2001.

11. ID-pharma BV. G-standaard, Kombi-ROM. Den Haag: WINAp; 2001.

12. Clayton D, Kaldor J. Empirical Bayes estimates of agestandardized relative risks for use in disease mapping. Biometrics 1987;43:671-81. 